\title{
OPTIMAL VEHICLE SUSPENSION CHARACTERISTICS FOR INCREASED STRUCTURAL FATIGUE LIFE
}

\author{
Braham Breytenbach $^{1}$ and Schalk Els ${ }^{1}$ \\ ${ }^{1}$ Department of Mechanical an Aeronautical Engineering, University of Pretoria, 0002 Pretoria, South Africa \\ braham7@gmail.com, Schalk.Els@up.ac.za
}

\begin{abstract}
Heavy off-road vehicle suspension systems face unique challenges. The ride comfort versus handling compromise in these vehicles has been frequently investigated using mathematical optimisation. Further challenges exist due to the large variations in vehicle sprung mass. A passive suspension system can only provide optimal isolation at a single payload. The designer of such a suspension system must therefore make a compromise between designing for a fullyladen or unladen payload state. This work deals with suspension optimisation for vehicle structural life. The paper mainly addresses two questions: 1) What are the suspension characteristics required to ensure optimal isolation of the vehicle structure from road loads? and 2) If such optimal suspension characteristics can be found, how sensitive are they to changes in vehicle payload? The study aims to answer these questions by examining a Land Rover Defender 110 as test vehicle. An experimentally validated non-linear seven degree-of-freedom mathematical model of the test vehicle is constructed for the use in sensitivity studies. Mathematical optimisation is performed using the model in order to find the suspension characteristics for optimal structural life for the vehicle under consideration. Sensitivity studies are conducted to determine the robustness of the optimal characteristics and their sensitivity to vehicle payload variation. Recommendations are made for suspension characteristic selection for optimal structural life.
\end{abstract}

Keywords: Off-road vehicles, structural life, mathematical optimisation, dynamic modelling

\section{Introduction}

Manufacturers in the commercial vehicle sector have great pressure on them to increase the payload capacity of the vehicle without exceeding the legal vehicle mass restrictions. This can only be achieved by reducing the mass of the vehicle structure. This is to be accomplished without compromising the reliability of the vehicle's structural and other systems.

The goal of reducing vehicle mass drives designers to explore the use of exotic materials, novel construction techniques and innovative structural geometry. The reduction of input loads to the vehicle structure must also be keenly considered. These loads may be due to payload requirements or road loads, passed to the vehicle structure through the tyres, wheels and suspension system. The focus here is on the selection of vehicle suspension characteristics as these parameters are under the control of the vehicle designer.

In order to address the problem some metric must be identified to represent the quality of the suspension isolation in terms of damage to the vehicle structure. The challenge in defining such a metric is that changes in load levels are not a direct measure of changes in fatigue damage to the structure. A simple parameter such as standard deviation of suspension forces will therefore not provide unambiguous insight into the influence of suspension characteristics on fatigue damage in the vehicle structure. The discussion of input loads to the vehicle structure naturally leads to the suggestion of cumulative fatigue damage as suitable metric.

Literature on the selection of suspension characteristics for ride comfort or handling can be found for virtually any type of vehicle. The amount of literature available on the selection of 
suspension characteristics for fatigue damage to the vehicle structure stands in sharp contrast to this. The focus seems to have been on the prediction of road loads on vehicle structures and subsequently fatigue life of these structures [1],[2].

Zeiler and Barkey [3] did however conduct an analytical study into the effect of suspension characteristics on fatigue damage. They used an unvalidated linear pitch bounce vehicle model combined with the Forman crack growth law to calculate the sensitivities of fatigue damage to spring and damper characteristics. Their results indicate a decreasing fatigue life when spring and damper rates are increased. No suggestion is made as to what the optimal characteristics may be.

The ideal vehicle suspension system would provide near optimal isolation at different speeds over varying road profiles for widely varying payloads. A passive system cannot function optimally under these varying conditions and will inevitably result in a compromised solution. The large changes in the sprung mass of heavy vehicles present even greater challenges in selecting suitable suspension characteristics. A laden vs. unladen compromise thus exists, which is in many ways analogous to the ride comfort vs. handling compromise so often investigated in vehicle dynamics research.

The promise of ideal behaviour over a wide range of operating conditions makes active suspension systems attractive for solving these challenges. It is however well known that the energy consumption of these systems make their use prohibitive. Semi-active or adaptive suspension systems offer many of the advantages of active systems at a fraction of the energy requirements and complexity, [4]. These systems have consequently been suggested to remedy the laden vs. unladen compromise in heavy vehicles, [4],[5].

\subsection{Chosen test platform}

The test vehicle chosen for the current study is a Land Rover Defender 110 fitted with an experimental hydro-pneumatic suspension system, referred to as the 4 State Semi-active Suspension System or $4 \mathrm{~S}_{4}$. The $4 \mathrm{~S}_{4}$ was developed as a solution to the ride comfort vs. handling compromise for off-road vehicles[6]. The system has the ability to switch semi-actively between four passive states. The four states are obtained by switching independently between a high and a low spring rate and a high and a low damping rate. The working principle of a $4 \mathrm{~S}_{4}$ suspension strut is illustrated in Fig. 1. The system also has load-levelling capability.

The system, as currently implemented on the Land Rover, only utilises two of the states. The two states (stiff spring, high damping and soft spring, low damping) are currently optimised for handling and ride comfort respectively. It is suggested that the system may have the potential to solve the problems associated with high payload variations by optimising the stiff spring and high damping characteristics for the fully laden vehicle while the soft spring and low damping characteristics are optimised for the unladen vehicle. Semi-active control then simply switches between the "unladen" condition (soft spring and low damping) and the "laden" condition (stiff spring and high damping) based on the vehicle payload.

\section{Experimental work}

The purpose of the experimental work was to gather data which could be used for the validation of a mathematical model of the test vehicle as well as to determine the relationship between the suspension force and the strain in the suspension mounting bracket. The vehicle was instrumented 
to measure body vertical accelerations at three locations, body pitch and roll velocities, all four suspension displacements, the pressure in each suspension strut and vehicle longitudinal velocity. Two of the accelerometers were placed below the rear passenger seats, while the third was attached to the top of the right front suspension strut. The recorded suspension pressure data was used to calculate an estimate of the force in the suspension struts.

A tension-compression load cell was fitted between the left rear suspension strut and the rear axle. The load cell measured the vertical force in the suspension strut directly. Two $0^{\circ}-45^{\circ}-90^{\circ}$ rosette type strain gauges were attached to the left rear suspension mounting tower on the vehicle chassis. The strain gauges were used to measure the strain in the suspension mounting due to the vertical suspension forces.

The vehicle dynamics was characterised over both discrete obstacles and random terrain as suggested in [7]. A trapezoidal bump was used as discrete obstacle. The random terrain traversed was the Belgian Paving at the Gerotek Test Facilities, [8]. The use of this specific terrain is attractive as the terrain profile has been measured to high accuracy using several methods, [9]. The measured terrain profiles were used as inputs to the vehicle model.

The Land Rover was driven at different speeds over each terrain type. The speed was kept constant by driving against the diesel engine's governor in gear. The suspension setting was also manually varied between the ride comfort and handling modes. Each run was repeated at least three times to gain an estimate of the repeatability of the tests. The left rear body vertical accelerations for three different runs over a symmetrical trapezoidal bump course are presented in Fig. 2. The vehicle was travelling at $15 \mathrm{~km} / \mathrm{h}$ with the suspension set to ride comfort mode. The data from the three runs is almost indistinguishable. The repeatability of the tests was found to be excellent. Similar repeatability was observed with the other measured parameters for all the test runs conducted.

\section{Mathematical modelling}

A mathematical model of the vehicle provides a powerful tool to the vehicle designer. A model must be as simple as possible to ensure low computational expense. It must however contain enough detail to capture the dynamics which it was intended to predict with sufficient accuracy. A vehicle designer cannot use a vehicle model in design studies with any confidence if the limitations of the model are not known through comparison with experimental results.

The requirement for simplicity of the vehicle model in this study was met by starting with a simple model. The model was then incrementally improved by adding complexity as dictated by the correlation with experimental data or indeed lack thereof.

The first attempt at modelling the dynamics took the form of a linear four degree of freedom pitch bounce model. The model consisted of three masses, representing vehicle sprung and unsprung masses, connected by linear springs and dampers.

Fig. 3 and Fig. 4 show the rear vertical acceleration and left rear suspension force from the simulation, superimposed on the measured results. The data is for a run at $15 \mathrm{~km} / \mathrm{h}$ over symmetrical trapezoidal bumps with the $4 \mathrm{~S}_{4}$ set to ride comfort mode. The results from the model show some resemblance to the measured data over discrete obstacles, but were not considered acceptable for the current purpose. 
The model was subsequently improved by introducing non-linear spring and damper characteristics as well as the effects the rubber bushings in the suspension trailing arms and rubber bump stops. Analysis of the suspension force measured with the load cell, compared to the suspension force calculated from the measured pressure revealed the presence of significant friction in the hydropneumatic suspension system, which was experimentally characterised and included in the model. A static friction model was employed. This greatly improved the model's correlation over discrete obstacles, as indicated in Fig. 5 and Fig. 6. Correlation over the random terrain was however still unsatisfactory. This was attributed to the absence of the roll degree of freedom, which becomes important on the rough, unsymmetrical Belgian paving terrain.

The model was extended to a seven degree of freedom, non-linear, full vehicle model as indicated in Fig. 7. The front and rear axles are modeled with vertical and roll degree of freedom each. The vehicle body has pitch, roll and vertical degrees of freedom. This results in a set of 7 nonlinear second order differential equations that are solved by numerical integration. The complete mathematical derivation of the equations of motion, as well as the non-linear spring and damper force characteristics and friction models are documented in [10] The model now captured the roll degrees of freedom which were absent in the pitch bounce model. The correlation over discrete obstacles was similar to the pitch bounce model. The quality of the correlation, by inspection, is excellent.

The correlation over the Belgian paving in terms of the RMS values of selected quantities is presented in Tables 1 to 4 . The data is presented for four runs at different speeds with suspension setting manually alternated between ride comfort and handling modes. The model correlation over the Belgian paving was much improved at high speed $(55 \mathrm{~km} / \mathrm{h})$, by the introduction of the additional degrees of freedom. The correlation at low speed $(15 \mathrm{~km} / \mathrm{h})$ still leaves room for improvement. The model can therefore not be used to make inferences about events at low speeds.

Some improvement in the model correlation may be gained by constructing a high fidelity multibody-systems model of the vehicle, which can include the non-linearities in suspension geometry. The linear approximation to the suspension kinematics currently employed is however thought to be reasonable assumption, when considering the simple suspension geometry on the Land Rover. The tyre model is thought to harbour the most potential for improvement.

Currently a linear point follower tyre model is employed, with experimentally determined stiffness and damping rate. On the rough terrain the point follower tends to "drop" into ruts which are filtered by the tyre's geometry on the real vehicle. Attempts to mimic this filtering by a rigid wheel travelling over the road profile have delivered limited success. Footprint or flexible ring tyre models should be investigated to improve the vehicle dynamics correlation in future work.

\subsection{Stress and damage prediction}

It has been shown thus far that the correlation of the developed model is of sufficient accuracy to predict road input loads to the vehicle structure at $55 \mathrm{~km} / \mathrm{h}$ based on the comparison of vehicle body acceleration and suspension force. The prediction of structural damage requires that these loads are translated to strains or stresses in the vehicle structure.

A quasi-static stress analysis approach was used to convert the predicted loads to strains and subsequently stresses in the vehicle suspension mounting. This approach can be applied in cases were a structure is operating in its linear (elastic) region, and where the frequency content of the applied load is well below the structures natural frequencies, [11]. 
Comparison of the strains (measured with the two tri-axial strain gauges on the suspension mounting) to the applied vertical force (measured with the load cell on the suspension strut) over various terrains at different speeds revealed that quasi-static analysis was indeed feasible. The measured strain which most accurately represented the strain due to suspension vertical load was identified. The identified strain channel combined with the measured vertical suspension force was then used to calculate a constant of proportionality or "stiffness" for the structure as indicated in Fig. 8. The constant could then be used to calculate the strains in the structure due to the vertical suspension force. The strain calculated by this method is within $5 \%$ of the measured strain, given the measured suspension force from runs over the Belgian paving at various speeds.

The strains were converted to stress using the uni-axial form of Hooke's law of elasticity. Range-pair-range cycle counting, as suggested in [12], was performed on the calculated stress histories to extract individual loading cycles. Miner's rule of damage summation was used to estimate the damage due to each cycle extracted. The effect of mean stresses was neglected. Miners rule of damage summation was used to estimate the damage from the simulated stress-strain histories. The S-N curve determined for a SANS class E weld [13] was used to represent the fatigue behaviour of the material. This choice was largely arbitrary, as the fatigue behaviour of the material was unknown and the prediction of the exact fatigue life of the structure was not of primary concern. The model correlation in terms of fatigue damage is also given in Tables 1 to 4 . An overview of this fatigue damage prediction methodology is given in Fig. 9.

The friction model used in the $4 \mathrm{~S}_{4}$ suspension struts should be further investigated to improve the fatigue damage correlation of the model. The static friction characteristic currently employed causes sharp suspension force changes as the suspension displacement reverses direction. This leads to damage over-prediction. Dynamic friction models may improve the damage correlation and should be investigated in future work.

\section{Mathematical optimisation}

The gradient-based Dynamic-Q mathematical optimisation algorithm developed by Snyman and Hay, [14], was chosen for the mathematical optimisation due to its proven efficiency and robustness when applied to vehicle suspension optimisation problems. The algorithm makes use of successive spherical quadratic approximations of the cost function, which are then solved by the LFOPC dynamic trajectory method. Dynamic-Q has been shown to be highly efficient at solving problems with severe inherent noise content, which is common when simulations are used for cost function evaluations or gradient approximations. The Dynamic-Q algorithm is described in detail in [15]. Great success has been achieved in applying the algorithm to the problems of suspension optimisation for ride comfort and handling [16,17,18]. Thoresson [16] employed central finite differences for gradient approximation instead of the less expensive forward finite differences usually employed. He found that the improved convergence due to more robust and less noisy gradient approximation was worth the added computational expense.

\subsection{Problem formulation}

The aim of the mathematical optimisation is to minimize the damage to the vehicle structure due to road input loads, by the selection of appropriate suspension spring and damper characteristics. The problem can be formulated as a standard optimisation problem: 
$\min _{w . r . t .} f(\bar{x}), \quad \bar{x}=\left[x_{1}, x_{2}, \ldots, x_{n}\right]^{T} \in \mathfrak{R}^{n}$,

subject to the constraints:

$$
g_{j}(\bar{x}) \leq 0, \quad j=1,2
$$

In the equations given above, $f(\bar{x})$ represents the objective function (or cost function) and $\bar{x}$ represents the vector of design variables.

These optimal characteristics are to be determined for the vehicle in the unladen condition and for a fully laden condition. The unladen condition sees the vehicle weighing in at $2190 \mathrm{~kg}$. The fully laden condition was chosen to be representative of the unladen to laden load variation observed in heavy trucks. Cole [19] states that the ratio of unsprung to sprung mass can be as low as 0.1 in fully laden vehicles of this type. This implies vehicle sprung mass of $4500 \mathrm{~kg}$ for the Land Rover. This load condition is similar to the fully laden mass of armoured versions of the Land Rover Defender.

The objective function, $f(\bar{x})$, is defined as the cumulative damage incurred by the vehicle when driving over a road consisting of $100 \mathrm{~m}$ of an ISO 8608 class A road [20] and 100m of the Gerotek Belgian paving at a constant speed of $55 \mathrm{~km} / \mathrm{h}$.

The design variables used in the optimisation are the non-linear spring and damper characteristics of the vehicle. The force displacement characteristic of the hydro-pneumatic spring is fully defined by the spring static gas volume, [6]. The baseline static volume is $0.3 \ell$ and the static volume was allowed to vary between 0.05 and $0.85 \ell$ in the optimisation.

The damper curve is not so easily defined by a single parameter. A set of four quadratic polynomials was fitted to the baseline force displacement characteristic [16]. The shapes and magnitudes of the polynomials are determined by six damper scale factors. The bump and rebound directions of the damper characteristic are each governed by three of the six damper scale factors. The damper scale factors were allowed to vary between 0.1 and 4 in the optimisation.

The optimisation process is also bounded by certain constraints. The suspension working space on the vehicle is fixed by the vehicle design and limited by rubber bump stops. It is undesirable that the suspension encounters its bump stops from both a fatigue damage and ride comfort perspective. A constraint was constructed to ensure that the optimal suspension characteristics do not allow the suspension to encounter the bump stops.

The optimal suspension characteristics should also be such that wheel hop is limited. Lack of damping in the suspension may cause large variations in vertical wheel load, which is detrimental to the longitudinal and lateral force generation capability of the tyre and therefore a safety concern, [4], [21]. High dynamic wheel load fluctuations are also a contributing factor for pavement fatigue failures, [22]. Thoresson [16] employed a wheel hop constraint which only allowed the wheels to loose ground contact for less than $10 \%$ of the total simulation time in his optimisation for ride comfort. Thoresson's constraint was included in the current study's optimisation for fatigue damage.

In a heavy vehicle application, road damage is also an important parameter to consider. Attempts 
to include a road damage constraint based on Sweatman's observations of the tyre Dynamic Load Coefficient (DLC) [23] have as yet proved unsuccessful. The DLC is defined as the ratio between the RMS dynamic tyre loads to the static tyre load. The DLC was chosen to represent the road damage in this study due to the fact that road damage is usually modelled as fourth power of the DLC. The reader is referred to [23] for a detailed discussion on pavement damage estimation.

The cost function, design variables and constraint functions were all scaled in an attempt to promote sphericality of the design space and aid in the rapid convergence of the Dynamic-Q algorithm. A gradient sensitivity study was performed to find an appropriate variable perturbation size for the gradient approximations. The gradient approximations were found to be well behaved for variable perturbations sizes ranging from $10^{-4}$ almost down to machine precision. A move limit of one fifth the radius of the region of interest was found to give the best convergence over a range of different starting points.

\subsection{Two-variable optimisation}

The optimisation methodology was developed and refined using a two-variable formulation described here. The spring static gas volume is defined as the first design variable, while the six damper scale factors are combined into a single damper scale factor representing the second design variable. The front and rear static gas volume as well as the front and rear damper characteristics are therefore the same in this approach. The two-variable formulation of the cost function allows one to visualise the cost function in three dimensional space. A surface plot of the cost function, for both the unladen and fully laden conditions, is given in Fig. 10 and 11. The cost function values in the plot have been scaled as percentages of the baseline damage. The baseline is defined as the damage in the unladen case with the baseline spring and damper characteristics, i.e. static gas volume $=0.3 \ell$ and all damper scale factors $=1$.

The cost functions in both cases indicate a largely uni-modal design space. Minima can be found in the low damping, soft spring region of the design space. The cost functions exhibit a large region of near minimum values.

An interesting observation which can be made is that in both cases the problem seems to be largely insensitive to the static gas volume. The cost function in the fully laden case does become more sensitive to spring stiffness as damping is decreased. The stiffness of the hydro-pneumatic spring is a hyperbolic function of static gas volume [6]. This is at least the partial cause of the cost function's low sensitivity to static gas volume at large static gas volumes.

The convergence histories for two optimisation runs from different starting points are plotted for both cost functions (Fig. 10 and 11.). The circular markers indicate points were function and gradient values were evaluated. The arrows indicate the direction of convergence. The convergence is generally well behaved, with the algorithm following a direct path to the minima. Deviations from this path are due to noisy gradient information or the hindrance by constraint functions. The reliability of the convergence deteriorated as the cost function entered the shallow dish-like region near the optima. The numerical noise is thought to dominate the gradient approximation in these regions of low gradient value.

In the unladen payload case the optimisation converged to a static gas volume ranging between 0.3-0.7 $\ell$, while the damper scale factor ranged between 0.2 and 0.4. The cost function values for these minima ranged between 24 and $28 \%$ of the baseline structural damage. A similar result was found for the fully laden case. The optimisation converged to static gas volumes ranging from 0.40 
to $0.85 \ell$, with damper scale factors ranging between 0.35 and 0.7 . The cost function value at the minima varied between 65 and $76 \%$ of the baseline damage.

The widely distributed near optimum points indicate very robust optima. In order to confirm this, a Monte Carlo simulation, using 500 cost function evaluations, was performed across the region to which the optimisation converged. The results of the simulation are presented in Fig. 12 and 13. The feasible function evaluations are indicated as circles while the crosses indicate infeasible points. The infeasible region in both plots is due to the violation of the suspension workspace constraint.

The selection of a robust minimum requires that the design variables lie far enough from the constraint function boundary. The robust optima were chosen such that a $10 \%$ variation in the design variable values would not cause a constraint violation.

The robust optimum for the unladen vehicle is found at a damper scale factor of 0.4 and a static gas volume of between 0.4 and $0.85 \ell$. The mean cost function value in this region is $29 \%$ with a standard deviation of $2.9 \%$ of the function value. The robust optimum for the fully laden vehicle is at static gas volumes between 0.5 and $0.85 \ell$ and a damper scale factor of 0.75 . The corresponding mean function value in the region is $86 \%$, while the coefficient of variation is $7.9 \%$ of the baseline damage.

The results for the unladen and fully laden cases are summarised in Table 5. The ride comfort and handling optima for the unladen case, as determined by Thoresson [16], have been included for comparison.

The fatigue damage optima and ride comfort optima for the unladen case are very similar. This result is not entirely unexpected. The fatigue damage optimum for the fully laden case requires a slightly larger static gas volume than for the unladen case. The large overlap of the static gas volumes required for the unladen and laden cases are due to the load-levelling operation of the hydro-pneumatic suspension system. The result should therefore not be extrapolated to nonlevelling suspension systems. The damper scale factor required for the fully laden vehicle is almost double that required for the unladen case.

\subsection{Multi-variable optimisation}

The optimal shape of the fatigue damage optimal damper characteristic is also of interest. A seven-variable formulation of the optimisation problem was defined using the static gas volume as well as the six independent damper scale factors. This formulation proved too complex and clear trends could not be distinguished from the results, i.e. there may be many diverse local minima. It is thought that the uni-modality of the optimisation problem is lost when multiple variables are considered.

A three-variable formulation of the optimisation problem was subsequently constructed in an attempt to reveal more distinct trends in the results. The three-variable formulation kept the static gas volume as design variable, but redefined the damper characteristic using two damper scale factors. The first scale factor governs the negative velocity (bump) region, while the second scales the positive velocity (rebound) region. The optimisation was conducted for both payload cases using the three-variable formulation. The resulting optima are listed in Table 6.

The observation can be made that the damper scale factor in the rebound direction is 
significantly reduced from that required by the two-variable optimisation optimum. Significant reductions in cost function value were also achieved. The cost function value for the unladen case was reduced to $25.3 \%$, while the cost function value for the fully laden case was $29 \%$ of baseline. As with the two-variable formulation the problem was relatively insensitive to changes in static gas volume and the damping required increased with vehicle payload.

The observations concerning the reduction in rebound damping and the associated improvement in fatigue damage can be explained by examining the suspension strut force responses to sinusoidal input. The strut response forces for both symmetric and asymmetric damper scale factors shown in Fig. 14. It can be seen that the force ranges for the asymmetric damper characteristic are significantly smaller than those for the symmetric damper characteristic. The reduced force ranges are thought to be the cause for the reduction in fatigue damage, when the asymmetric damper characteristic is employed.

It is concluded that an asymmetric damper characteristic can significantly improve fatigue performance. This stands in contrast to the damper characteristics required for ride comfort and handling. In his optimisation for ride comfort and handling Thoresson [16] found that the optimal damper characteristics were required to be symmetric. Assuming that a ride comfort optimal damper characteristic is also fatigue damage optimal is therefore not necessarily correct.

\section{Conclusions}

The seven degree of freedom non-linear vehicle model gave excellent correlation over discrete obstacles and good correlation at high speed over rough, asymmetrical random terrain. The model's poor correlation over the random terrain at low speed is attributed to the point follower tyre model employed. Footprint or flexible ring tyre models are recommended for investigation in future work to improve the vehicle dynamics correlation. The static model for the friction in the $4 \mathrm{~S}_{4}$ suspension struts should be refined to include dynamic effects if the fatigue damage correlation is to be improved.

The model was used in the mathematical minimisation of the fatigue damage to the vehicle structure for both a fully laden and unladen payload case. The hydro-pneumatic spring static gas volume and a damper scale factor where defined as design variables in a two variable formulation of the optimisation problem. Visualisations of the cost functions revealed that the optimisation problems are uni-modal, with minima in the soft spring, low damping region of the design space. The cost functions were found to be insensitive to variation of the static gas volume for both load cases. The insensitivity is attributed to the fact that the stiffness of the hydro-pneumatic spring is a hyperbolic function of the static gas volume.

The optimisation converged to a large region of feasible and near optimal values, for both payload conditions. The chosen optima were shown to be highly robust in terms of variation of both spring and damper characteristics.

The optimal suspension characteristics for fatigue damage in the unladen case are similar to the characteristics required for ride comfort. The spring characteristic required for the fully laden condition is a subset of the optimum for the unladen case. The optimal damper scale factor for the fully laden case is however almost double that required for the unladen vehicle. The problem is thus more sensitive to damper characteristic with respect to changing payloads. The load-levelling operation of the hydro-pneumatic suspension system contributes to the insensitivity of the static gas 
volume.

A three-variable formulation of the optimisation problem was used in order to determine the optimal shape for the damping curve. The investigation showed that damage to the vehicle structure could be reduced if the rebound damping could be minimised.

Due to the problem's general lack of sensitivity to changes in static gas volume, the implementation of a system such as the $4 \mathrm{~S}_{4}$ cannot be recommended based structural fatigue life considerations alone. The most advantage would be gained from the use of a suspension system with ride height control and a two-state semi-active damper. The situation might still favour the $4 \mathrm{~S}_{4}$ if handling criteria are taken into consideration.

\section{References}

[1] Medepalli, S., Rao, R., 2000, Prediction of road loads for fatigue design - a sensitivity study, International Journal of Vehicle Design, 23 (1/2), p. 161-175.

[2] Conle, F. A., Mousseau, C. W., 1991, Using vehicle dynamics simulations and finite-element results to generate fatigue life contours for chassis components, International Journal of Fatigue, 13 (3), pp. 195-205.

[3] Zeiler, T.A., Barkey, M.E., 2001, Design sensitivities of fatigue performance and structural dynamic responses in an automotive application, Structural and Multidisciplinary Optimisation, 21, pp. 309-315.

[4] von Glasner, E.-C., Goehring, E., Povel, R., Schuetzner, P., 1993, Analysis of Intelligent Suspension Systems for Commercial Vehicle, SAE Technical Paper no. 933008, pp. 35-43

[5] Bode, O., von Glasner, E.-C., Holnkaus, H., Pflug, H.-C., Povel, R., 1997, Einfluss von Fahrzustand und Fahrwerk auf die Vertikaldynamik von Nutzfahrzeugen, Automobiltechnische Zeitschrift, 99 (7/8), pp.396-402.

[6] Els, P.S., 2006, The ride comfort vs. handling compromise for off-road vehicles, Unpublished $\mathrm{PhD}$ Thesis, University of Pretoria, South Africa.

[7] Letherwood, M.D., Gunter, D.D., 2001, Ground vehicle modelling and simulation of military vehicles using high performance computing, Parallel Computing, 27, pp. 109-140.

[8] http://www.armscorbusiness.com/Subsites/Gero-tek/Gerotek01_landing.asp (accessed on 2009/09/18)

[9] Els, P.S., Becker, C. M., 2009, Profiling of Rough Terrain, Proceedings: $11^{\text {th }}$ European Regional Conference of the International Society for Terrain-Vehicle Systems, 5-8 October 2009 -Bremen, Germany.

[10] Breytenbach, H.G.A., 2010, Optimal vehicle suspension characteristics for increased structural fatigue life. Unpublished M.Eng Dissertation, University of Pretoria, South Africa, http://upetd.up.ac.za/thesis/available/etd-09172010-190101/ accessed on 28 Dec 2010.

[11] Haiba, M., Barton, D.C., Brooks, P.C., Levesley, M.C., 2002, Review of life assessment techniques applied to dynamically loaded automotive components, Computers and Structures, 80, pp. 481-494.

[12] Dowling, N.E., 2007, Mechanical Behaviour of Materials: Engineering Methods for Deformation, Fracture, and Fatigue, 3rd Ed. Pearson - Prentice Hall. 
[13] Standards South Africa, 2005, South African National Standard SANS 10162: The Structural Use of Steel, SANS 10162-1:2005 $2^{\text {nd }}$ Ed.

[14] Snyman, J. A., Hay, A. M., 2001, The Dynamic-Q Optimization Method: An Alternative to SQP?, Computers and Mathematics with Applications, 44, pp. 1589-1598.

[15] Snyman, J.A., 2005, Practical Mathematical Optimisation - An Introduction to Basic Optimisation Theory and Classical and New Gradient-Based Algorithms, Springer, pp. 119-125.

[16] Thoresson, M.J., 2007, Efficient Gradient-Based Optimisation of Suspension Characteristics for An Off-Road Vehicle, Unpublished PhD Thesis, University of Pretoria, South Africa. http://upetd.up.ac.za/thesis/available/etd-08042008-093103/ accessed on 28 Dec 2010

[17] Thoresson, M.J., Uys, P.E., Els, P.S. and Snyman, J.A., 2009, Efficient optimisation of a vehicle suspension system, using a gradient-based approximation method. Part 1. Mathematical modelling, Mathematical and Computer Modelling, Vol. 50, pp. 1421-1436.

[18] Thoresson, M.J., Uys, P.E., Els, P.S. and Snyman, J.A., 2009, Efficient optimisation of a vehicle suspension system, using a gradient-based approximation method. Part 2. Optimisation results, Mathematical and Computer Modelling, Vol. 50, pp. 1437-1447.

[19] Cole, D. J., 2001, Fundamental Issues in Suspension Design for Heavy Road Vehicles, Vehicle System Dynamics, 35 (4-5), pp. 319-360.

[20] International Organization of Standardization, 1995, International Standard ISO 8606: Mechanical Vibration - Road surface profiles - Reporting of measured data, ISO 8608: 1995(E).

[21] Uys, P.E., Els, P.S, Thoresson, M., 2006, Suspension settings for optimal ride comfort of offroad vehicles travelling on roads with different roughness and speeds, Journal of Terramechanics, 44, pp.163-175.

[22] Cebon, D., 1989, Vehicle-Generated Road Damage: A Review, Vehicle System Dynamics, 89, pp.107-150.

[23] Sweatman, P.F., 1983, A Study of Dynamic Wheel Forces in Axle Group Suspensions of Heavy Vehicles, Australian Road Research Board, Special Report No. 27. 
Table 1: Belgian paving correlation: $15 \mathrm{~km} / \mathrm{h}, 4 \mathrm{~S} 4 \mathrm{soft}$

Table 1: Belgian paving correlation: $15 \mathrm{~km} / \mathrm{h}, 4 \mathrm{~S}_{4}$ soft

\begin{tabular}{|l|l|l|l|}
\hline Quantity & Measured & Simulation & Error \\
\hline $\begin{array}{l}\text { Rear Accel. } \\
\text { RMS [m/s }{ }^{2} \text { ] }\end{array}$ & 1.401 & 1.993 & $42 \%$ \\
\hline $\begin{array}{l}\text { Left Rear Force } \\
\text { RMS [N] }\end{array}$ & 752 & 1105 & $47 \%$ \\
\hline Damage & $0.55 \times 10^{-6}$ & $1.88 \times 10^{-6}$ & $239 \%$ \\
\hline
\end{tabular}


Table 2: Belgian paving correlation: $55 \mathrm{~km} / \mathrm{h}, 4 \mathrm{~S} 4$ soft

Table 2: Belgian paving correlation: $55 \mathrm{~km} / \mathrm{h}, 4 \mathrm{~S}_{4}$ soft

\begin{tabular}{|l|l|l|l|}
\hline Quantity & Measured & Simulation & Error \\
\hline $\begin{array}{l}\text { Rear Accel. } \\
\left.\text { RMS [m/s }{ }^{2}\right]\end{array}$ & 3.149 & 3.276 & $-4.0 \%$ \\
\hline $\begin{array}{l}\text { Left Rear Force } \\
\text { RMS [N] }\end{array}$ & 1715 & 1687 & $-1.6 \%$ \\
\hline Damage & $2.41 \times 10^{-6}$ & $2.28 \times 10^{-6}$ & $-5.1 \%$ \\
\hline
\end{tabular}


Table 3: Belgian paving correlation: $15 \mathrm{~km} / \mathrm{h}, 4 \mathrm{~S} 4$ hard

Table 3: Belgian paving correlation: $15 \mathrm{~km} / \mathrm{h}, 4 \mathrm{~S}_{4}$ hard

\begin{tabular}{|l|l|l|l|}
\hline Quantity & Measured & Simulation & Error \\
\hline $\begin{array}{l}\text { Rear Accel. } \\
\text { RMS [m/s }{ }^{2} \text { ] }\end{array}$ & 3.173 & 5.061 & $55 \%$ \\
\hline $\begin{array}{l}\text { Left Rear Force } \\
\text { RMS [N] }\end{array}$ & 2007 & 2868 & $43 \%$ \\
\hline Damage & $6.0 \times 10^{-6}$ & $20.6 \times 10^{-6}$ & $243 \%$ \\
\hline
\end{tabular}


Table 4: Belgian paving correlation: $55 \mathrm{~km} / \mathrm{h}, 4 \mathrm{~S} 4$ hard

Table 4: Belgian paving correlation: $55 \mathrm{~km} / \mathrm{h}, 4 \mathrm{~S}_{4}$ hard

\begin{tabular}{|l|l|l|l|}
\hline Quantity & Measured & Simulation & Error \\
\hline $\begin{array}{l}\text { Rear Accel. } \\
\text { RMS [m/s }{ }^{2} \text { ] }\end{array}$ & 6.106 & 6.616 & $-8.4 \%$ \\
\hline $\begin{array}{l}\text { Left Rear Force } \\
\text { RMS [N] }\end{array}$ & 3776 & 3676 & $-2.6 \%$ \\
\hline Damage & $12.7 \times 10^{-6}$ & $16.1 \times 10^{-6}$ & $27 \%$ \\
\hline
\end{tabular}


Table 5: Optimal suspension characteristics for the two-variable

Table 5: Optimal suspension characteristics for the two-variable optimisation

\begin{tabular}{|c|c|c|}
\hline \multicolumn{3}{|l|}{ Unladen vehicle } \\
\hline & $\begin{array}{l}\text { Static Gas } \\
\text { Volume }\end{array}$ & $\begin{array}{l}\text { Damper } \\
\text { Scale } \\
\text { Factor }\end{array}$ \\
\hline Fatigue damage & $0.3-0.85 \ell$ & 0.4 \\
\hline Ride comfort & $0.5 \ell$ & 0.3 \\
\hline Handling & $0.1 \ell$ & 3 \\
\hline \multicolumn{3}{|c|}{ Fully laden vehicle } \\
\hline & $\begin{array}{l}\text { Static Gas } \\
\text { Volume }\end{array}$ & $\begin{array}{l}\text { Damper } \\
\text { Scale } \\
\text { Factor }\end{array}$ \\
\hline Fatigue damage & $0.5-0.85 \ell$ & 0.75 \\
\hline
\end{tabular}


Table 6: Optimal suspension characteristics for the three-variab

Table 6: Optimal suspension characteristics for the three-variable optimisation

\begin{tabular}{|l|l|l|l|}
\hline \multicolumn{3}{|l|}{ Unladen vehicle } \\
\hline & $\begin{array}{l}\text { Static Gas } \\
\text { Volume }\end{array}$ & $\begin{array}{l}\text { Damper } \\
\text { Scale } \\
\text { Factor } \\
\text { [Bump] }\end{array}$ & $\begin{array}{l}\text { Damper } \\
\text { Scale } \\
\text { Factor } \\
\text { [Rebound }]\end{array}$ \\
\hline $\begin{array}{l}\text { Fatigue } \\
\text { damage }\end{array}$ & $0.3-0.85 \ell$ & 0.49 & 0.17 \\
\hline Fully laden vehicle & $\begin{array}{l}\text { Static Gas } \\
\text { Volume }\end{array}$ & $\begin{array}{l}\text { Damper } \\
\text { Scale } \\
\text { Factor } \\
\text { [Bump] }\end{array}$ & $\begin{array}{l}\text { Damper } \\
\text { Scale } \\
\text { Factor } \\
\text { [Rebound }\end{array}$ \\
\hline & & 0.6 & 0.10 \\
\hline $\begin{array}{l}\text { Fatigue } \\
\text { damage }\end{array}$ & $0.5-0.85 \ell$ & 0.6 \\
\hline
\end{tabular}


Fig. 1: 4S4 working principle

Valve 3

Accumulator 2

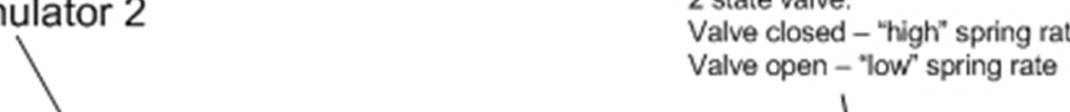

alve closed - "high" spring rate

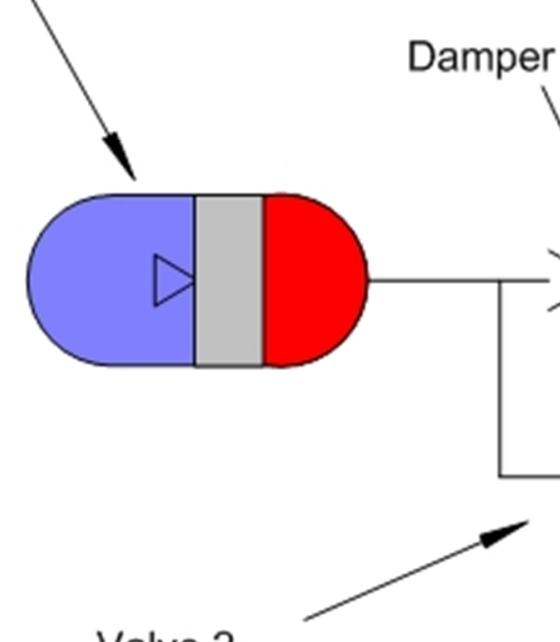

Valve 2

2 state valve:

Valve closed - "high" damping

Valve open - "low' damping

" spring rate

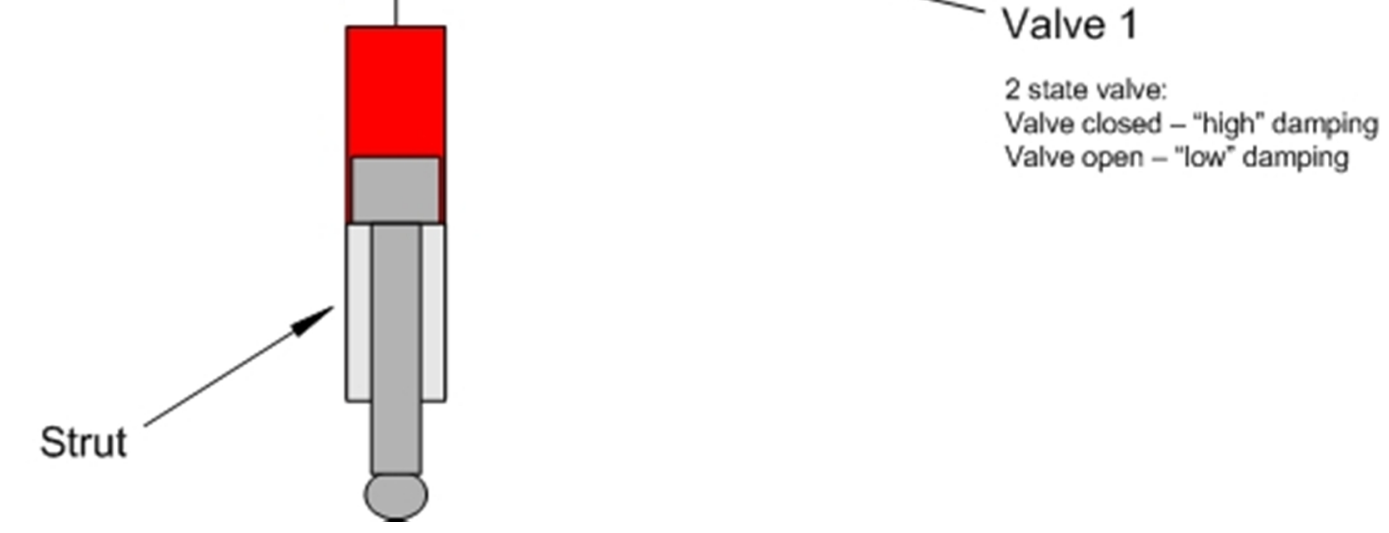

Accumulator 1

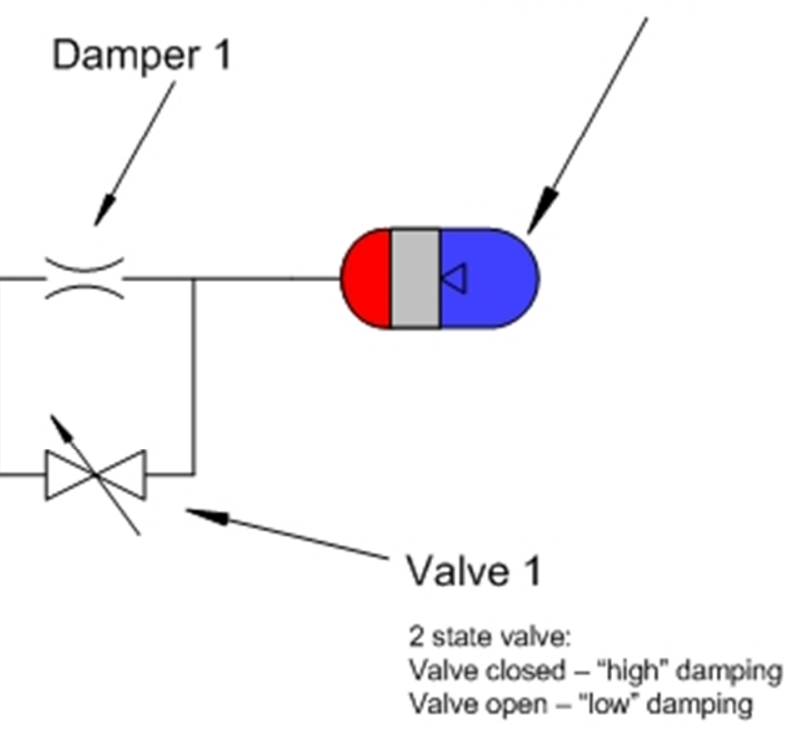


Fig. 2: Comparison of vertical acceleration for three runs over symmetrical trapezoidal bumps

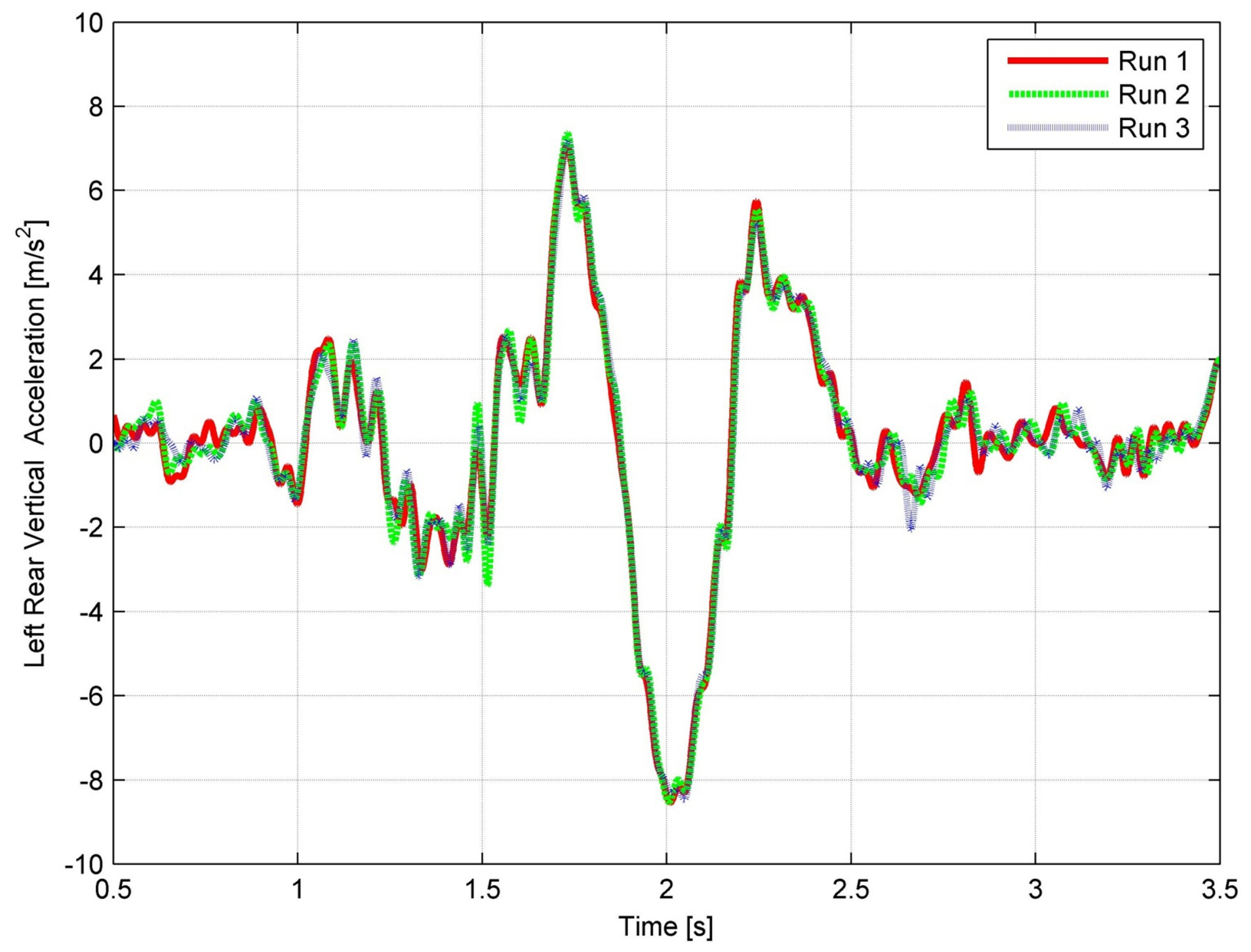


Fig. 3: Linear 4DOF pitch-bounce model: rear vertical acceleration

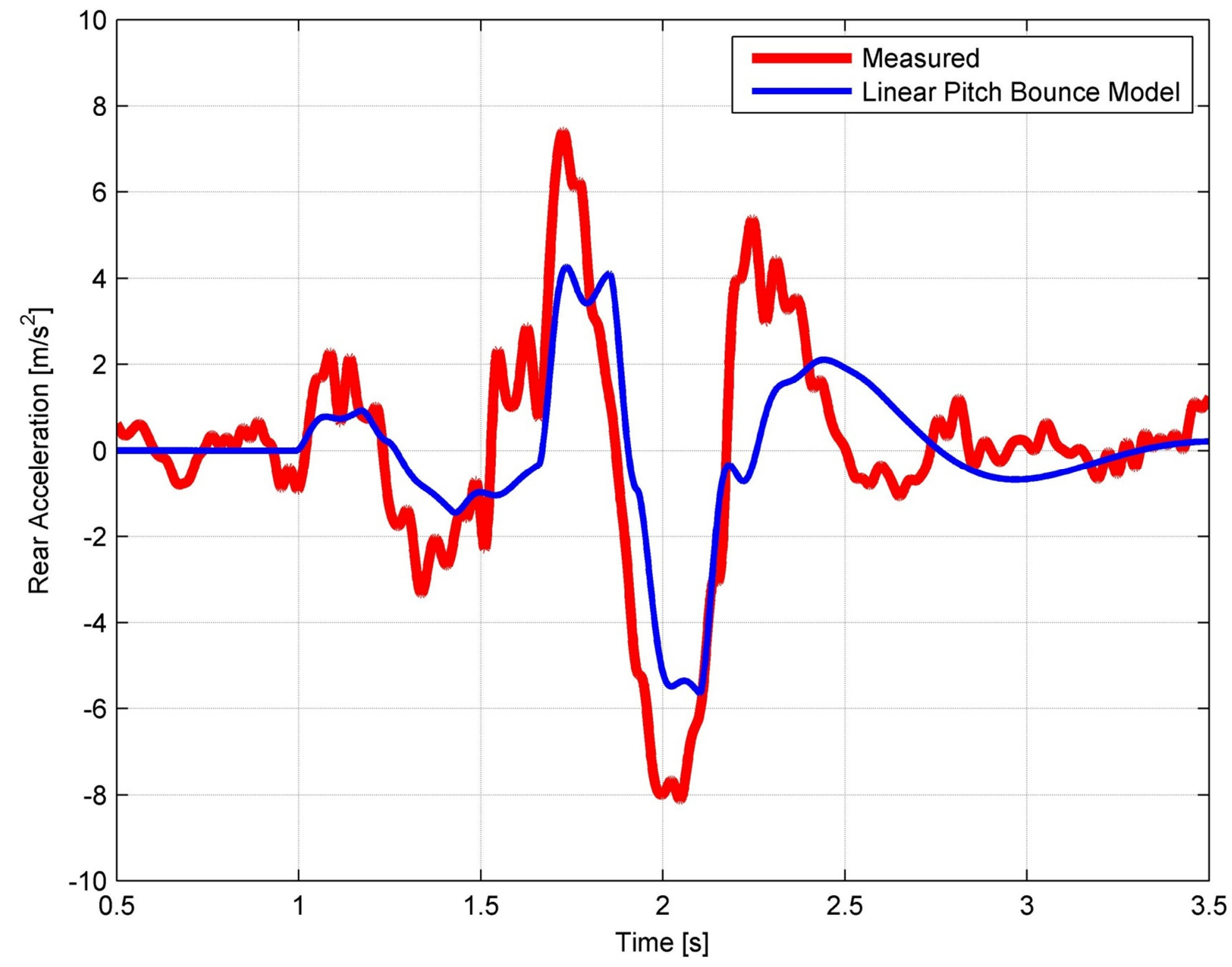


Fig. 4: Linear 4DOF pitch-bounce model: rear suspension force

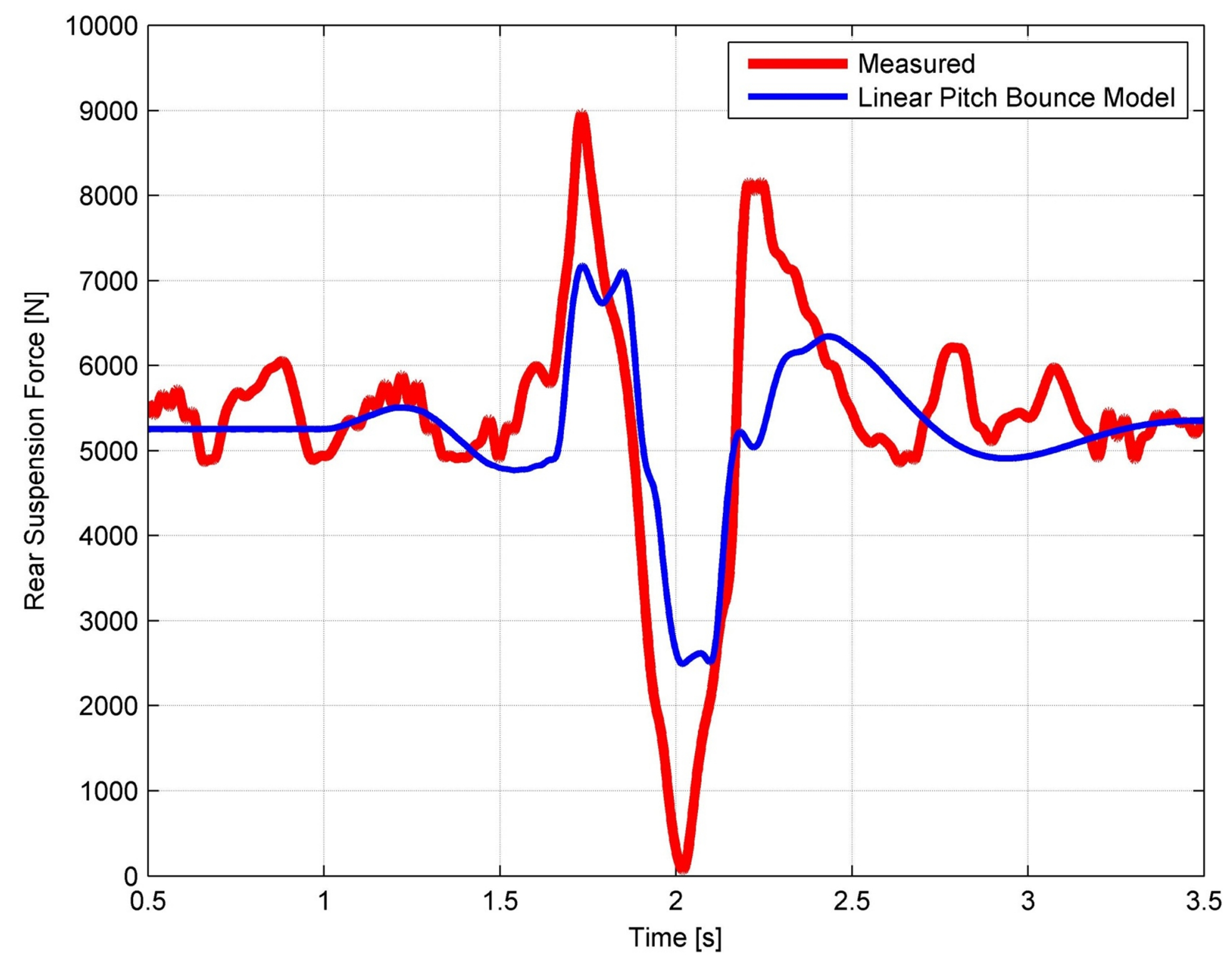


Fig. 5: Non-linear 4DOF pitch-bounce model: rear vertical acceleration

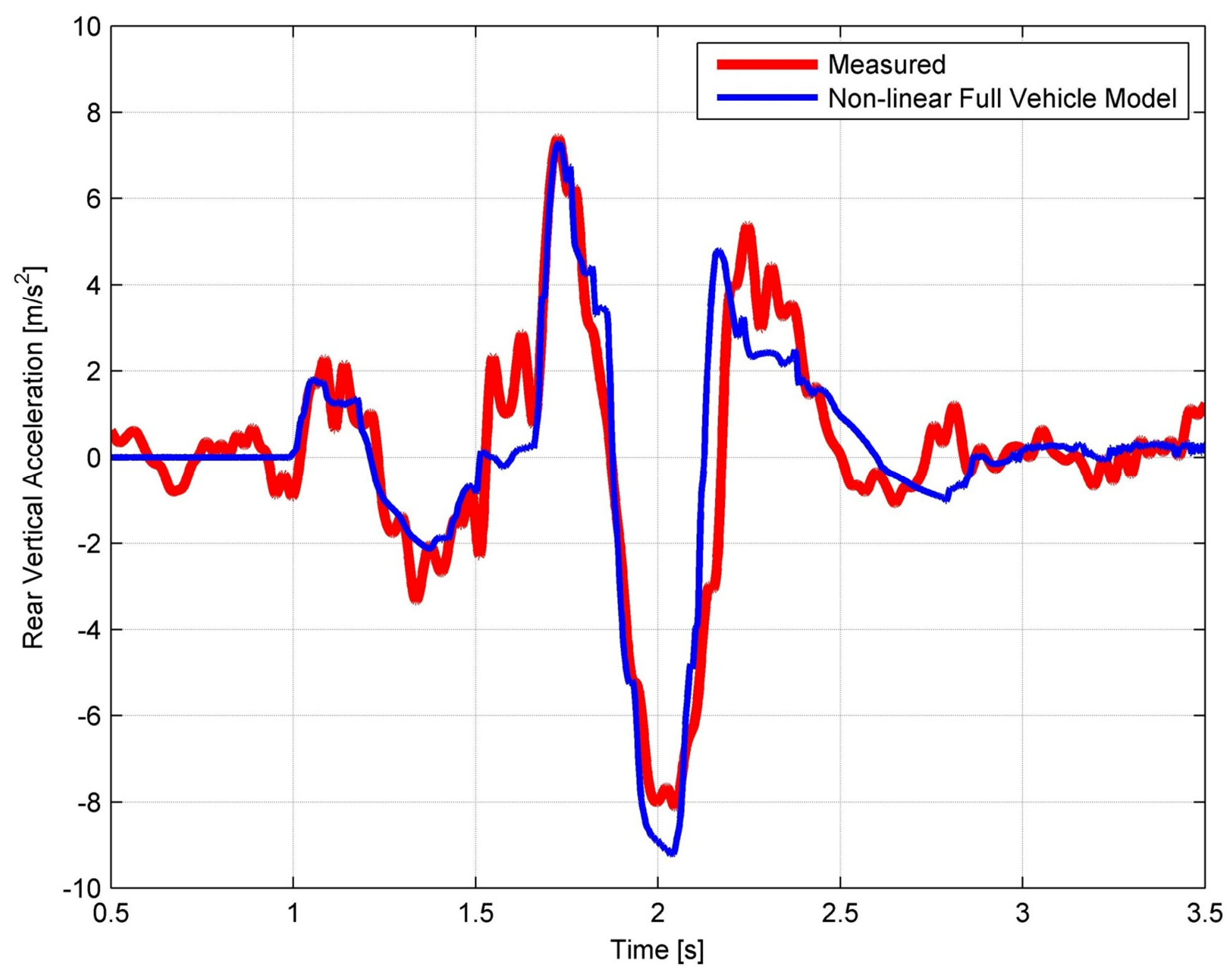


Fig. 6: Non-linear 4DOF pitch-bounce model rear suspension force

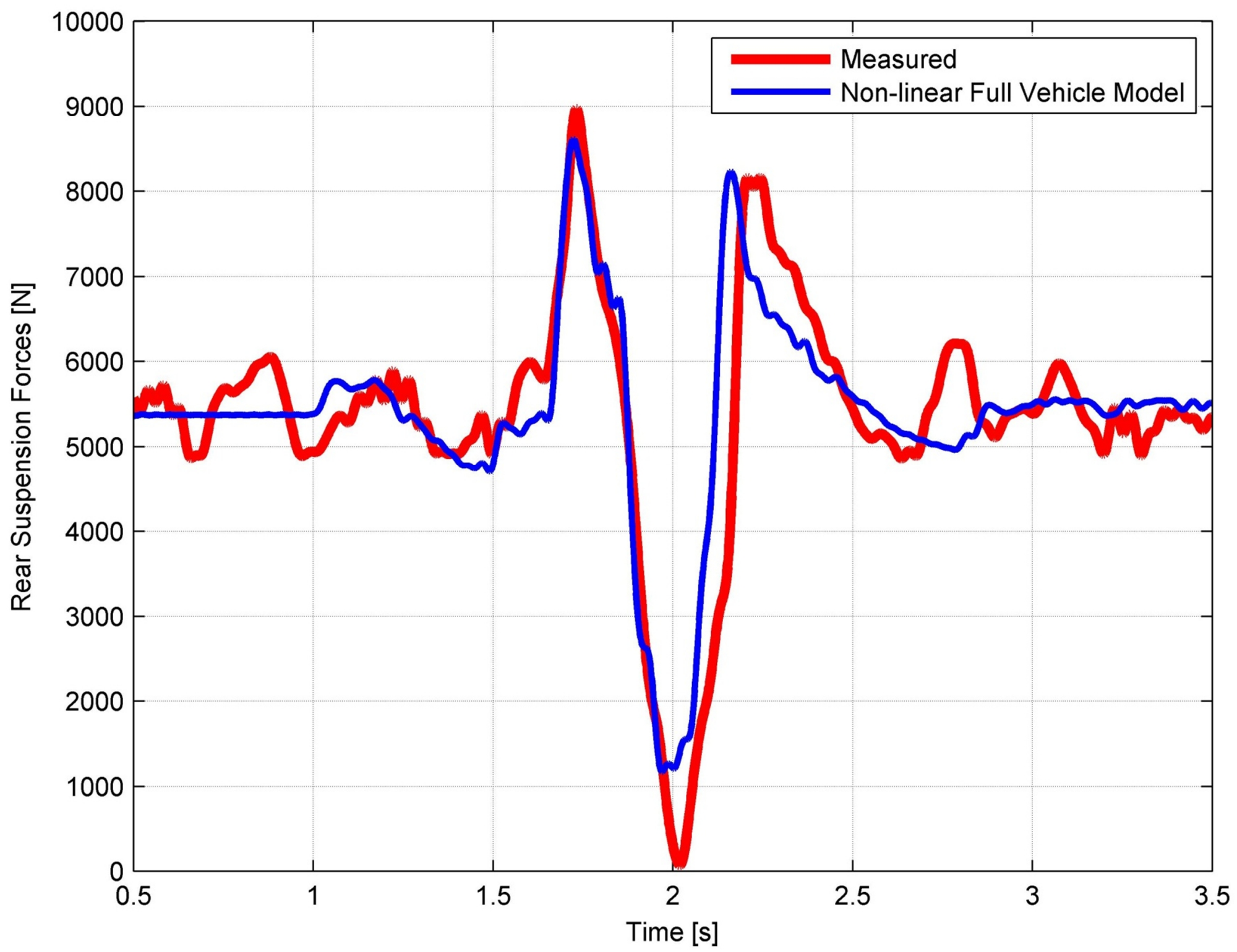


Fig. 7: 7DOF model schematic

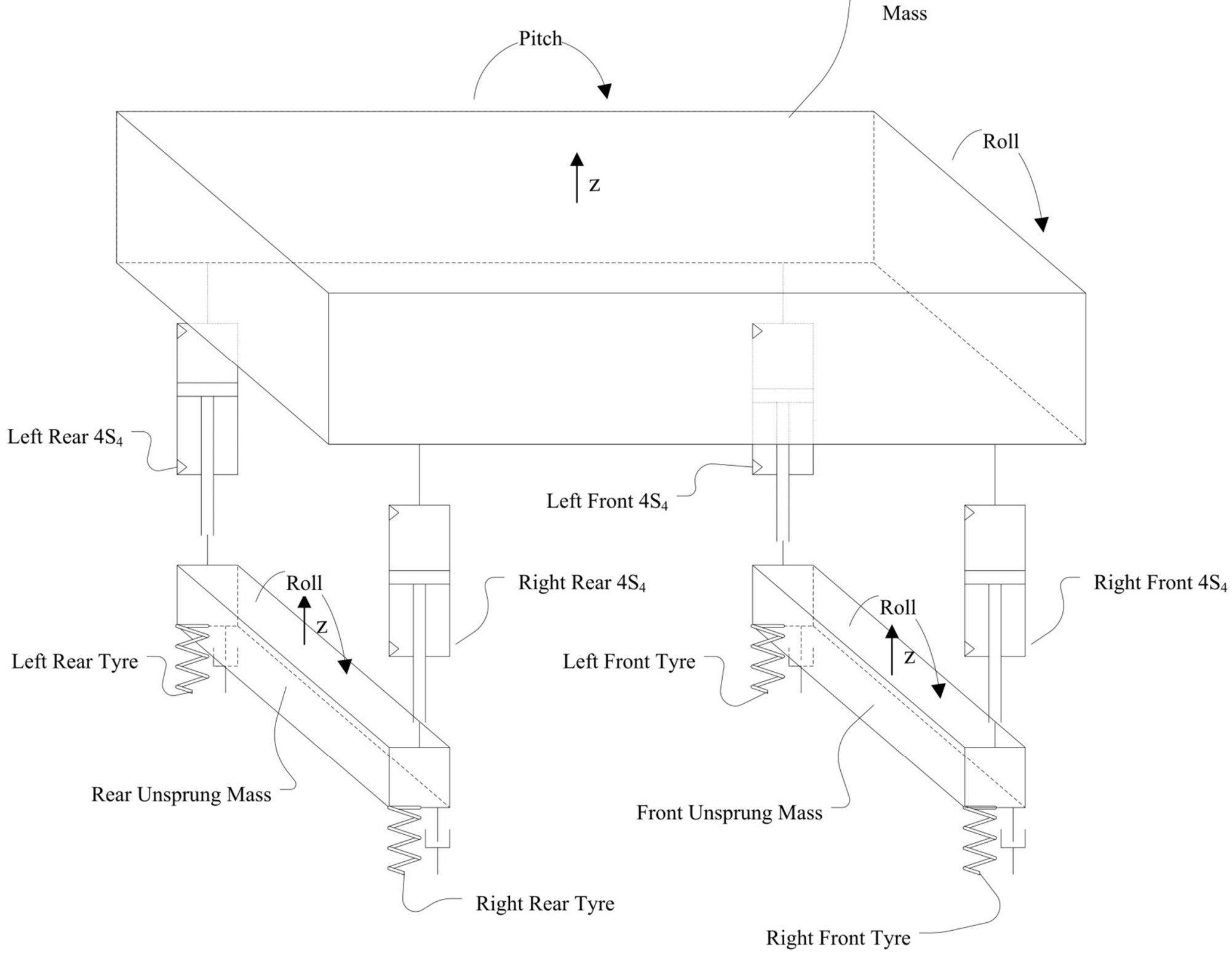


Fig. 8: Relationship between suspension force and strain on suspension bracket

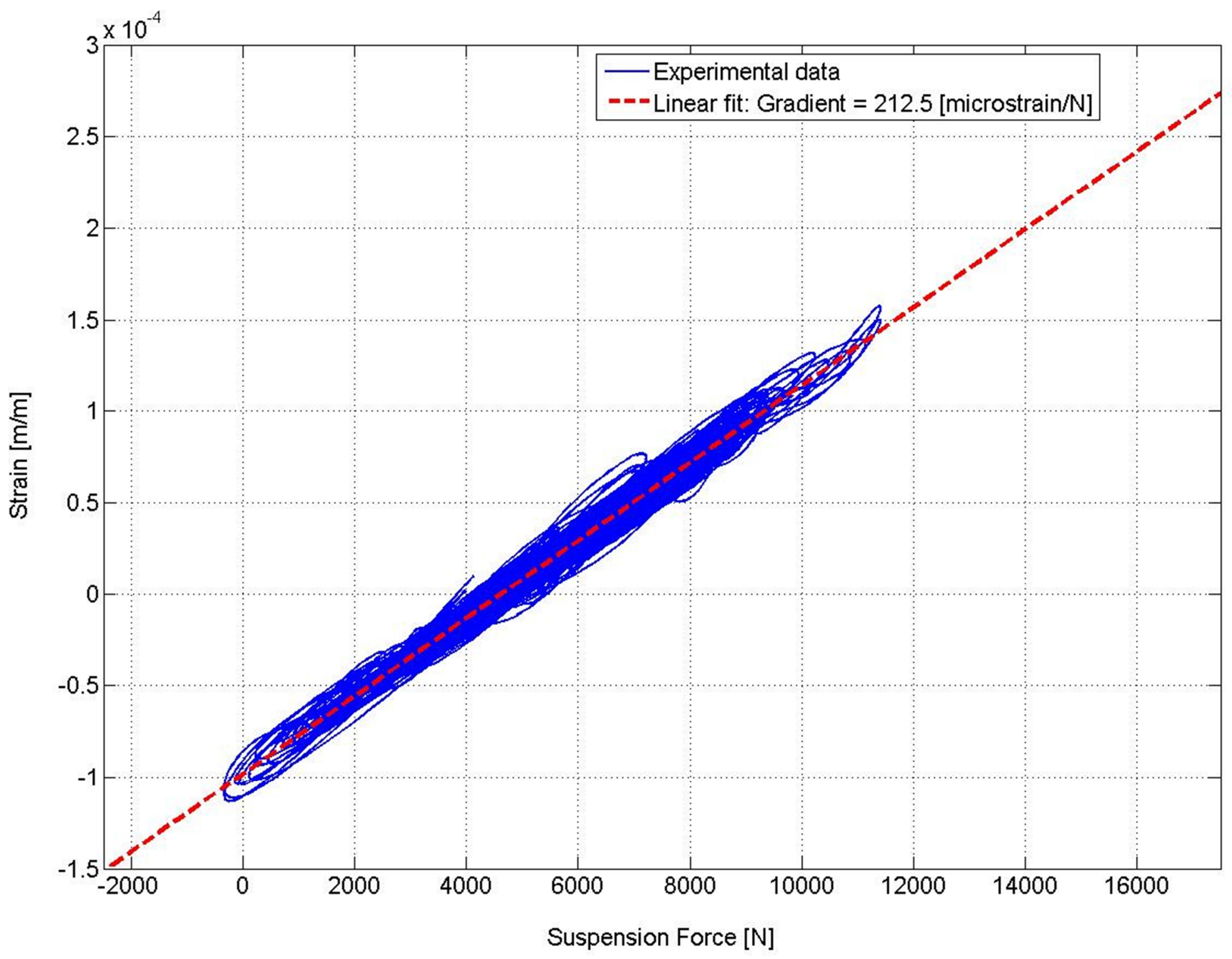


Fig. 9: Overview of fatigue damage calculation procedure

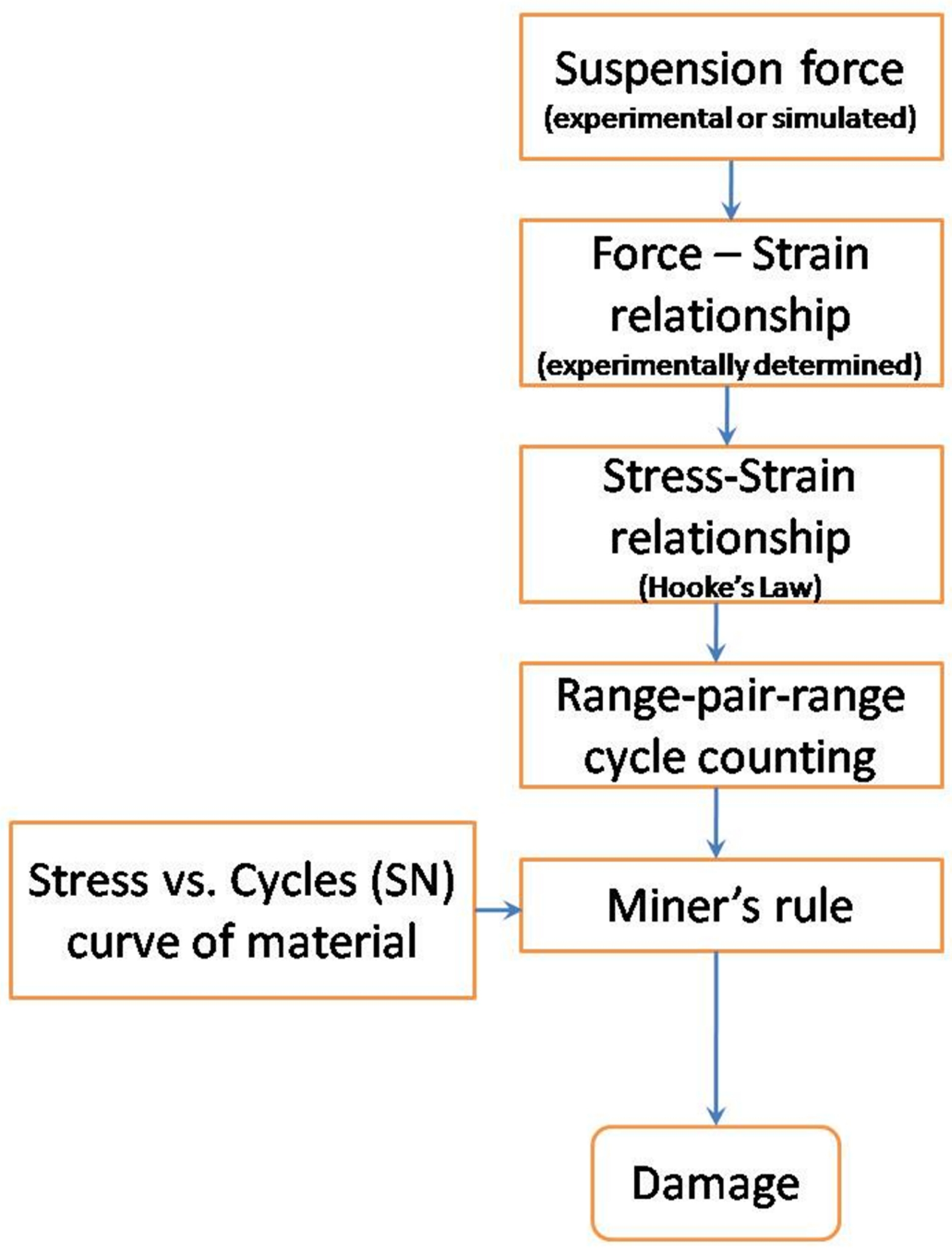


Fig. 10: Cost function plot for the unladen vehicle

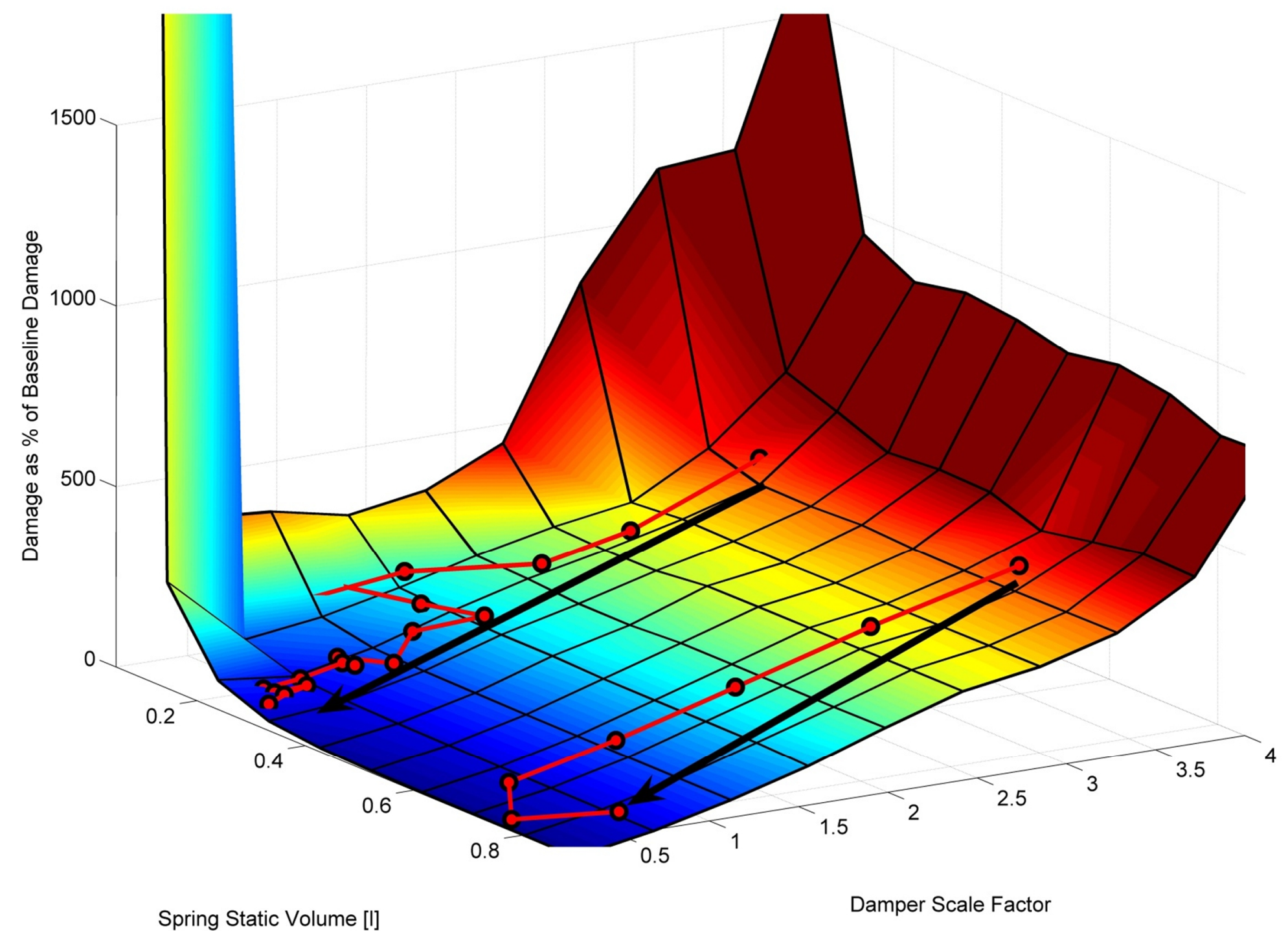


Fig. 11: Cost function plot for the fully laden vehicle

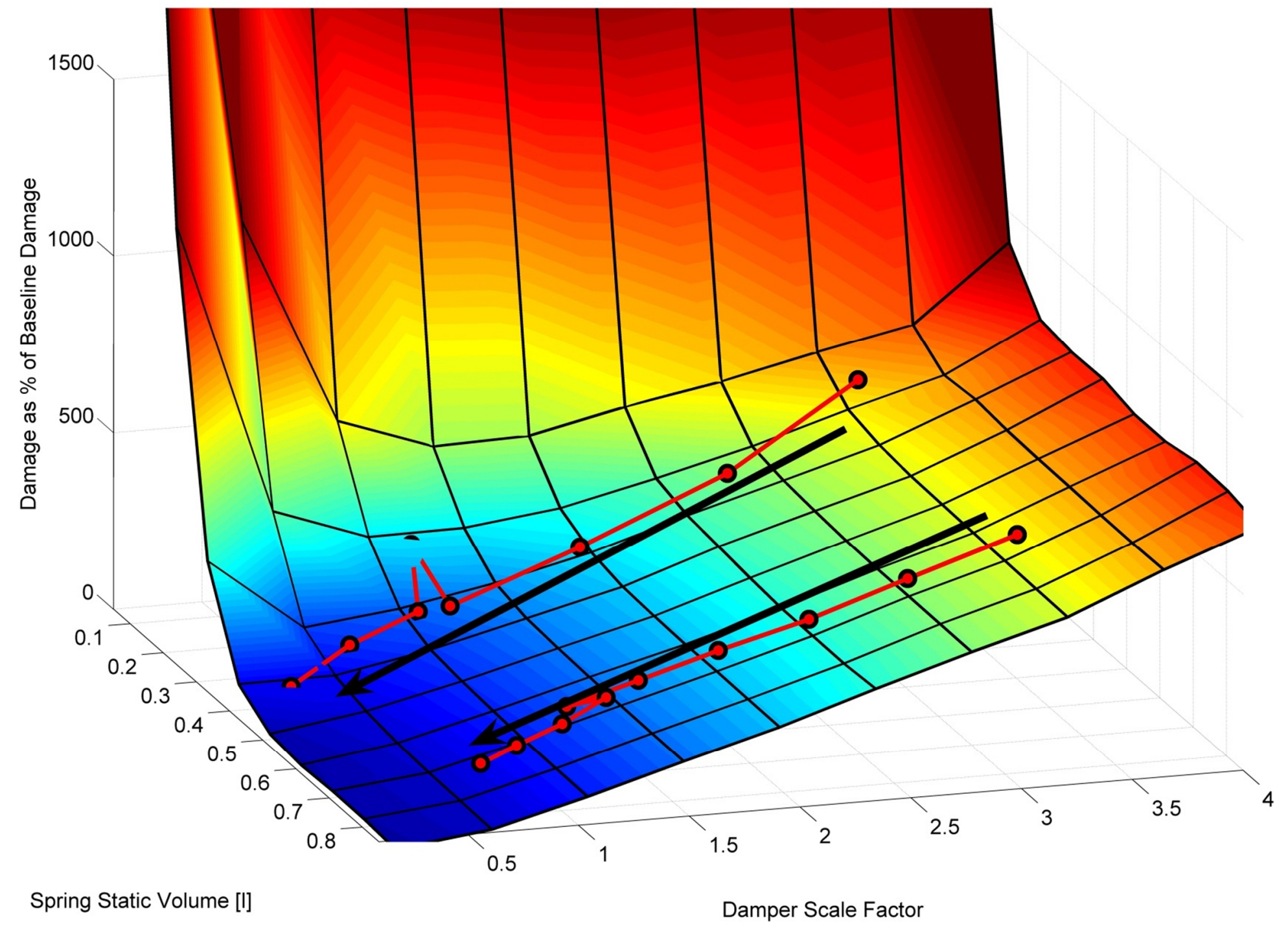


Fig. 12: Contour plot of the cost function for the unladen vehicle

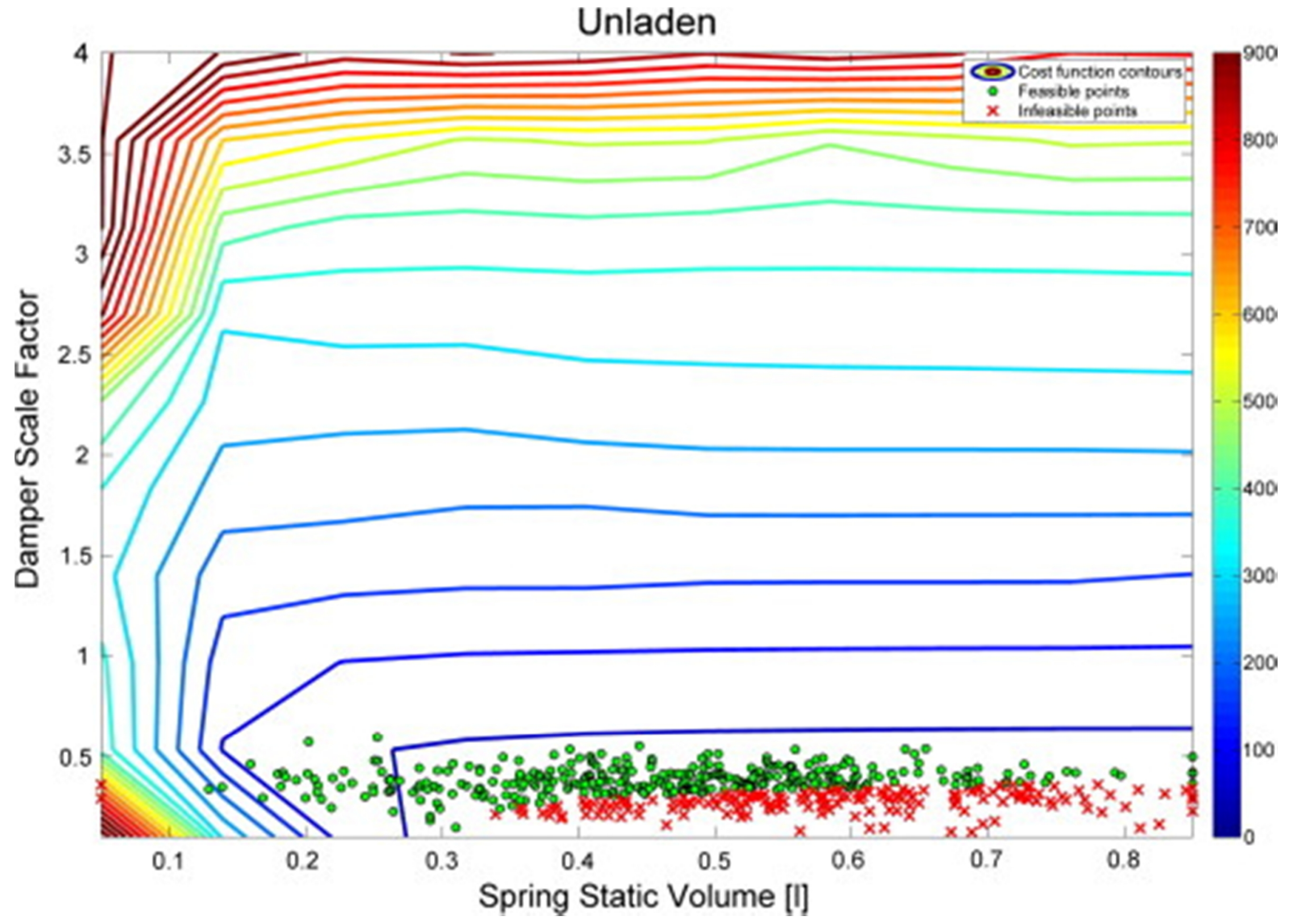


Fig.13: Contour plot of the cost function for the fully laden vehicle

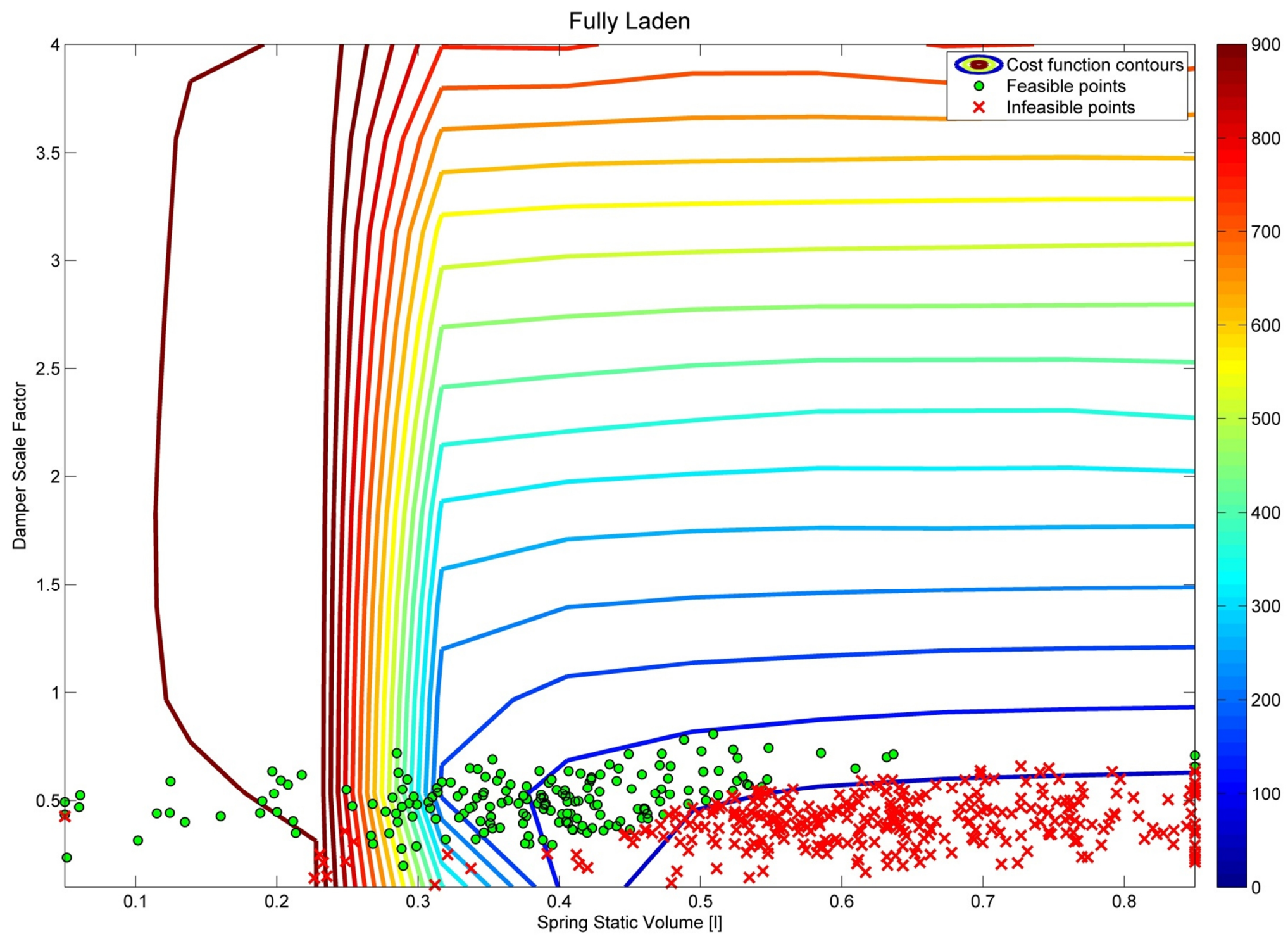


Fig.14: Suspension strut force response to sinusoidal input

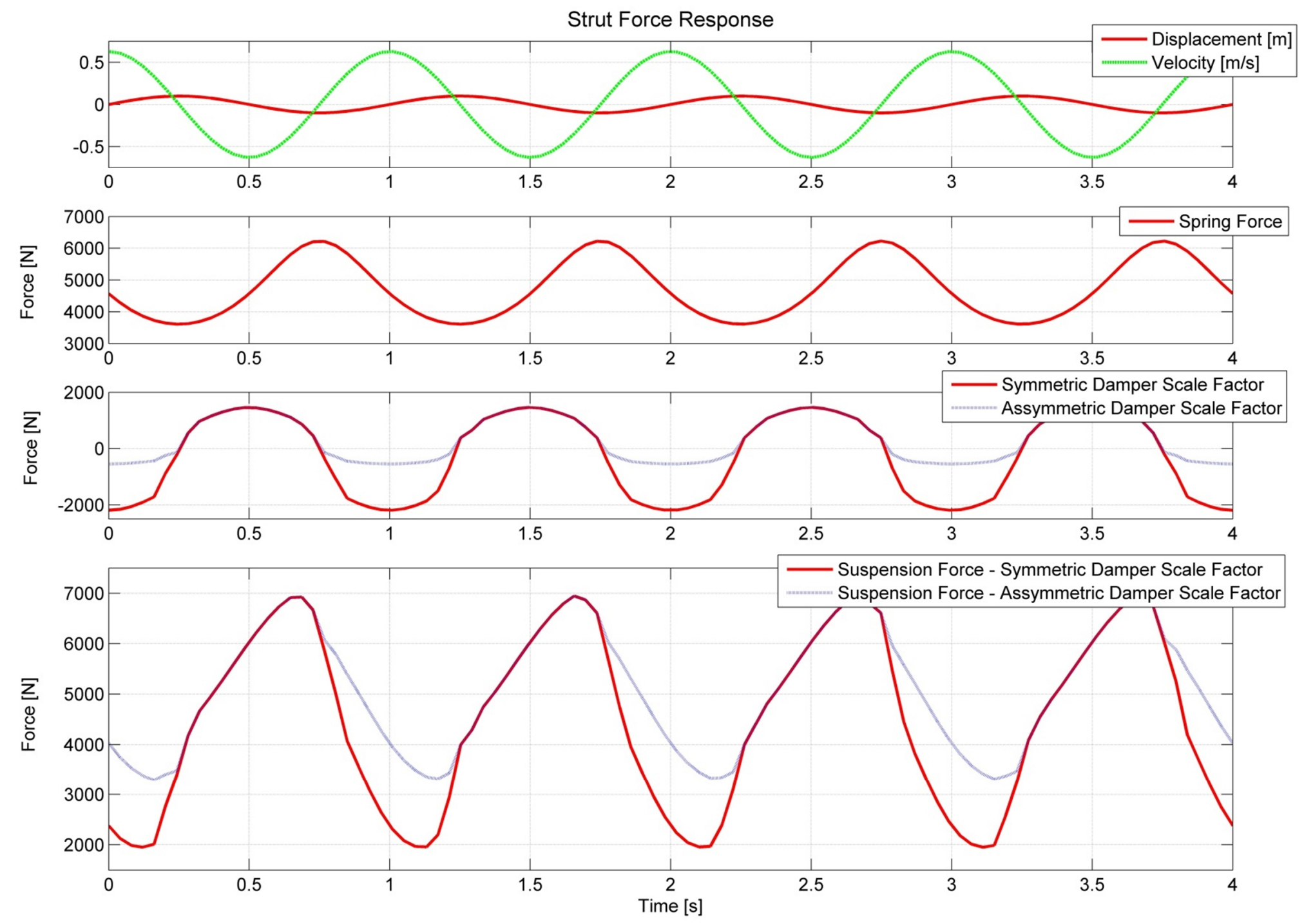

